\title{
PROTAGONISMOS INSTÁVEIS DOS PRINCÍPIOS DE REGULAÇÃO E INTERFACES PÚBLICO/PRIVADO EM EDUCAÇÃO*
}

\author{
Almerindo Janela Afonso
}

\begin{abstract}
RESUMO: Ao longo da modernidade capitalista, no espaço de crescente afirmação de fronteiras nacionais, construindo e afirmando posiçōes e relaçōes desiguais, o Estado, o mercado e a comunidade foram os principais actores da regulação social. $\mathrm{O}$ protagonismo de um deles, geralmente o Estado, tendia a ser acompanhado pela retracção, cerceamento ou subordinação de cada um dos outros, ou dos dois em simultâneo, em graus muito distintos consoante as conjunturas históricas, as mudanças sociais, culturais, económicas e político-ideológicas. Esses protagonismos instáveis dos (velhos) princípios de regulação social têm sido confrontados com as profundas mudanças e transições das últimas décadas, sucedendo-se as interpenetraçōes, os hibridismos e ambivalências, em contextos agora marcados (também) por protagonismos emergentes de outros modos de regulação social, a nível nacional, internacional e transnacional. As interfaces público/privado, e a pluralidade de expressôes de mercado e quase-mercado em educação, podem ser lidas tendo em mente esse pano de fundo.
\end{abstract}

Palavras-chave: Princípios de regulação social. Interfaces público/privado em educação. Mercado e quase-mercado.

* Este texto surgiu na sequência do convite que me foi dirigido para participar, em dezembro de 2009, em Campinas, no II Seminário Brasileiro de Educação - "Os desafios contemporâneos para a educação brasileira e os processos de regulação". Nesta ocasiāo, em que foram comemorados os 30 anos de existência do Centro de Estudos Educação e Sociedade (CEDES), pude aproveitar de momentos muito ricos de aprendizagem e de convívio pessoal e intelectual com renomados colegas brasileiros e estrangeiros. Por estas e outras razôes, sou grato ao CEDES e seu colegiado, não podendo deixar de referir, de modo particular, o trabalho decisivo, expressivo e militante da profa Ivany Pino, tanto na coordenação deste importante projecto institucional, como da prestigiada revista Educação \& Sociedade.

** Doutor em Sociologia da Educação e membro do Centro de Investigação em Educação (CIEd) da Universidade do Minho (Portugal).E-mail: ajafonso@ie.uminho.pt 
Protagonismos instáveis dos princípios de regulação e interfaces público/privado...

\title{
UNSTABLE PROTAGONISMS OF THE PRINCIPLES OF REGULATION AND PUBLIC/PRIVATE INTERFACES IN EDUCATION
}

\begin{abstract}
Throughout the course of capitalist modernity, in a space of growing defence of national borders, building and entrenching unequal positions and relations, the State, the market and the community have been the leading actors of social regulation. The protagonism of one (usually the State) tended to be accompanied by the retraction, curtailment or subordination of the others, simultaneously or not, to very different degrees according to the historical context and social, cultural, economic and political/ideological changes. These unstable protagonisms of the (old) principles of social regulation have been confronted with the profound changes and transitions of the last few decades, making way for the inter-penetrations, hybridisms and ambivalences, in contexts now (also) marked by protagonisms that have emerged from other forms of social regulation, at a national, international and transnational level. The public/ private interfaces, and the plurality of market and quasi-market expressions in education, can be read with this vaster backdrop.
\end{abstract}

Key words: Principles of social regulation. Public/private interfaces in education. Market and quasi-market.

$\mathcal{A}$ bordar as interfaces entre o público e o privado remete para importantes questôes prévias, algumas das quais podem ser relacionadas com os princípios estruturantes de regulação social e respectivas interacçôes. A estas questôes podem ainda somar-se as que dizem respeito às mudanças trazidas pelas agendas da globalização hegemónica, com destaque para algumas repercussões no campo educacional vindas da transnacionalização neoliberal do capitalismo e da crescente mercantilização (ou mercadorização) da vida social, não sendo, em qualquer dos casos, elas próprias indiferentes ou estranhas à acção de algumas organizaçôes internacionais e supranacionais. Fica assim esboçado um roteiro possível para reflectir, ainda que sucintamente, sobre as interfaces público/privado no campo da educação e das políticas públicas.

\section{Estado, mercado e comunidade: protagonismos instáveis}

Quando tomamos em consideração a modernidade capitalista, ${ }^{1}$ podemos dizer que o exercício da regulação social assentou essencialmente 
em três princípios fundamentais: o Estado, o mercado e a comunidade. ${ }^{2}$ Historicamente, portanto, estes princípios emergem e afirmam-se, de forma bastante desigual e não raras vezes contraditória, através de processos de longa duração, que vão reconstruindo a sua própria identidade, reafirmando as suas especificidades e delimitando as suas funções e fronteiras (sociais, políticas, culturais e simbólicas), em interacções protagonizadas alternadamente, sobretudo entre o Estado e o mercado, com predomínio frequente do primeiro, e a subsequente subalternização e duradoura colonização da comunidade. Apenas com o objectivo de melhor compreensão de algumas afirmações neste texto, considere-se que o mercado e a comunidade, sendo conceitos distintos, estão muitas vezes implícitos na designação mais genérica de sociedade civil, marcando, com isso, uma oposição (discutível) a tudo o que não é Estado. ${ }^{3}$ Há, no entanto, perspectivas teórico-conceptuais que assentam no contrário, isto é, que pressupõem uma concepção de Estado e sociedade civil que não traduzem necessariamente esta oposição, ou, então, noções outras que colocam em evidência as mediações e interpenetraçôes das várias combinações possíveis entre a comunidade, o mercado e o Estado (ver, por exemplo, Estêvão, 1998).

Numa breve análise retrospectiva, Boaventura de Sousa Santos refere que, ao longo de todo o século XIX, "o princípio do Estado e o princípio do mercado colidiram frequentemente na demarcação de áreas de cumplicidade/complementaridade e de domínio exclusivo". Mais precisamente, como acentua ainda este mesmo autor,

No período do capitalismo liberal (...) a unidade do Estado assentava na distinção entre Estado e sociedade civil e na especificidade funcional do Estado. A sociedade civil e, acima de tudo, as relaçôes de mercado eram concebidas como auto-reguladas, e era ao Estado que cabia garantir essa autonomia. O instrumento mais crucial da autonomização da sociedade de mercado foi o direito privado, complementado por medidas fiscais, monetárias e financeiras, destinadas quase sempre a corrigir os desequilíbrios resultantes de deficiências e ou imperfeições do mercado. (Santos, 2000, p. 135)

Posteriormente, já nos finais do século XIX, a crescente densificação da sociedade capitalista manifestou-se na "expansão extraordinária do princípio do mercado", o que criou problemas e disfuncionamentos vários, nomeadamente aqueles que derivaram da concentração de capital 
Protagonismos instáveis dos princípios de regulação e interfaces público/privado...

e da proliferação de monopólios, que acabaram por exigir uma maior intervenção do Estado. Continuando a seguir Santos (2000), esta intervenção teve como consequência mais imediata a transformação da distinção entre Estado e sociedade civil e o esbatimento das fronteiras entre ambos, não sem que o Estado acabasse, por razões várias, por fortalecer a sua capacidade de regulação. A expressão disto mesmo culminou, durante o século Xx, com o desenvolvimento do fordismo e com novas formas de viabilizar a gestão económica e política: respectivamente, o keinesianismo e o Estado-providência, cujo relativo sucesso, nos países centrais, se estendeu até aos anos de 1970 (cf. Santos, 2000, p. 136-137). Segue-se um outro período de transformações do capitalismo e da democracia, que se iniciou, justamente, com a crise desse mesmo fordismo e do Estado-providência, abrindo caminho para o que veio a ser um novo e acentuado protagonismo do mercado - "um excesso de sentido que invade o princípio do Estado e o princípio da comunidade" (idem, ibid., p. 143). Chegámos assim aos tempos mais recentes em que os novos ícones (enquanto representaçóes mais comuns destas mudanças) remetem para a emergência do neoliberalismo e para a expansão de uma economia global, com o consequente esbatimento do papel anterior do Estado, agora cada vez mais incapaz de regular com sucesso a própria economia nacional. Neste contexto, por razôes que têm também a ver com a suposta e crescente dificuldade do Estado para gerir e dar conta das demandas sociais, o princípio da comunidade acabou por ganhar uma presença e uma dinâmica mais fortes, e com maior autonomia, ao ponto de voltarmos a reconhecer a necessidade de uma sociedade civil mais activa (ou, até mesmo, de uma sociedadeprovidência), que possa, pelo menos em parte, contrabalançar conjunturalmente os défices de investimento público do Estado e os problemas criados pelos excessos do mercado.

Mas os protagonismos e interacções entre o Estado e a sociedade civil (nas várias acepções, ou de mercado ou de comunidade ou de ambos) também foram diferenciados em função dos regimes políticos. Assim, por exemplo, se considerarmos apenas o contexto europeu e o período posterior à Segunda Guerra Mundial, verifica-se que o Estado teve um forte protagonismo, quer em sociedades com regime capitalista democrático, quer em sociedades com regime capitalista ditatorial, quer em sociedades com regime socialista (não democrático). Nos casos em que esse protagonismo assumiu a forma de Estado-providência, o 
aparelho político-administrativo procurou manter o controlo político da economia e a regulamentação da acção do mercado no interior das fronteiras nacionais. Noutros contextos, nos casos em que ocorreu um protagonismo estatal exacerbado, como o das ditaduras militares latino-americanas ou outras ditaduras em regimes capitalistas europeus, ou naquelas situações em que houve um forte controlo sobre a sociedade em termos culturais e político-ideológicos, acompanhado do desenvolvimento de uma economia socialista centralmente planificada, ou a sociedade civil foi fortemente constrangida em termos de iniciativa política (Nogueira, 1998), ou, para além disso, a existência e promoção do mercado foram impedidas ou fortemente cerceadas por serem incompatíveis com o sistema. No primeiro caso, a sociedade civil, como esfera autónoma dos cidadãos, tendeu a ser pouco activa, dado o intervencionismo e capacidade do Estado no atendimento das demandas sociais; no segundo caso, a sociedade civil não se constituiu sequer como esfera autónoma dos cidadãos, tendo sido, não raras vezes, profundamente desvitalizada sob o peso do totalitarismo estatal e dos aparelhos de coerção. ${ }^{4}$ Seja como for, nestes como noutros casos, nomeadamente quando a própria sociedade civil se confunde ou interpenetra com o Estado, fica sublinhado que as experiências concretas, as perspectivas político-ideológicas e as teorizações relativas à sociedade civil são muitas e antagónicas. Vejamos, sucintamente, até que ponto algumas destas questões estão ou não presentes em décadas mais recentes.

Num contexto político e económico predominantemente neoliberal, emergiu uma nova centralidade da sociedade civil e, ao mesmo tempo, passaram a coexistir concepções, representações e novas expectativas em torno do seu papel, muitas vezes em profunda divergência com essa ideologia. Não se pode, por isso, afirmar que tenha vindo a prevalecer uma concepção neoliberal de sociedade civil, ainda que esta concepção esteja também muito presente. Com efeito, a crise dos Estados-providência, a redefinição do papel do Estado e a reconfiguração dos espaços público e privado, num contexto de crescente exacerbação da ideia e importância do mercado e de mudanças profundas em termos de valores e visões do mundo, ressignificaram a importância cultural e social das iniciativas não estatais e induziram uma espécie de representação light de sociedade civil que, numa perspectiva mais radicalizada e conotada com uma certa hipermodernidade, se confunde muitas vezes com o lugar de afirmação de estratégias individualistas 
Protagonismos instáveis dos princípios de regulação e interfaces público/privado...

e de pulverização de identidades. Ao mesmo tempo, tem vindo a fortalecer-se uma outra representação de sociedade civil, politicamente mais densa e impactante, como lugar de explicitação de movimentos sociais contra-hegemónicos e de construção de articulações colectivas e organizativas de interesses transversais. Neste novo contexto, a sociedade civil pode ser também (e é muitas vezes) um lugar de resistência ao discurso e orientações dominantes, mas, mesmo assim, só raramente continua a ser entendida como arena privilegiada de luta de classes pela hegemonia (na acepção gramsciana).

No discurso neoliberal (ou mesmo no discurso da chamada terceira via), trata-se, antes, de uma acepção de sociedade civil que, consoante as nuances político-ideológicas ou as delimitações mais pragmáticas, ora significa mercado, ora significa comunidade, ora significa a mobilização simultânea e a interacção dos dois - agora chamados a ser parceiros, mediadores ou mesmo protagonistas em processos (supostamente não conflituais) de articulação com o Estado (cf., por exemplo, Lima \& Afonso, 2006). Uma destas possibilidades é precisamente aquela em que a sociedade civil, como comunidade que actua através de uma pluralidade de organizações e associações não lucrativas, se constitui como um espaço ou uma rede de interacções com relativa autonomia face ao Estado e ao mercado, não deixando, todavia, de os intersectar e de com eles conviver (e por eles ser, em parte, condicionada). São vistas hoje como iniciativas muito emblemáticas desta nova e supostamente mais activa e criativa sociedade civil as que, por exemplo, se inscrevem na economia social, na economia solidária, no empreendedorismo social ou, mais genericamente, no chamado terceiro sector. ${ }^{5} \mathrm{~A}$ análise mais profunda destas iniciativas, ainda que partindo de perspectivas muito divergentes, não deixa de mostrar a crescente instabilidade e porosidade do Estado, do mercado e da comunidade como princípios de regulação social.

Além disso, os acontecimentos mais recentes que desencadearam a actual crise económica e financeira do capitalismo também revelam que os consensos e os protagonismos em torno dos princípios de regulação (sobretudo o do Estado e o do mercado) são provisórios e instáveis. Se, nos últimos trinta anos, o pensamento único insistiu nos benefícios do mercado e nas consequências malévolas do crescente peso e intervenção do Estado, no presente momento parece que o Estado volta a ser a solução para todas as crises. 
Há aqui, todavia, algo que continua impreciso e que os discursos e análises parecem desconhecer ou fazer esquecer. Se recuarmos um pouco no tempo, veremos que, quando ocorreu a viragem neoliberal, em finais dos anos de 1970 e inícios dos de 1980, sobretudo em alguns países centrais como os EUA e a Inglaterra, não foram poucas as vozes, vindas sobretudo de sectores mais ortodoxos, a reclamar e anunciar as vantagens do Estado-minimo. Mas a retracção profunda do papel do Estado, que esta designação sugeria (cf. Nozick, 1988), nunca se concretizou, como o demonstram os próprios governos da nova direita, cuja fórmula política foi, antes, a de um Estado forte e uma economia livre (cf. Gamble, 1994; Afonso, 1999). Em convergência com essa fórmula, o chamado Consenso de Washington reforçou a tónica numa articulação mais híbrida e acabou por marcar a agenda. A este propósito, a forma como Santos (2006, p. 321) descreve esta mudança é elucidativa:

O Estado fraco, que emerge do Consenso de Washington, só é fraco ao nível das estratégias de hegemonia e de confiança. Ao nível da estratégia de acumulação é mais forte do que nunca, na medida em que passa a competir ao Estado gerir e legitimar no espaço nacional as exigências do capitalismo mundial. Não se trata, pois, da crise do Estado em geral, mas de um certo tipo de Estado. Não se trata do regresso puro e simples do princípio do mercado, mas de uma nova articulação, mais directa e mais íntima, entre o princípio do Estado e o princípio do mercado.

Directa ou indirectamente relacionada com esta constatação, e ao contrário do que vem sendo afirmado em alguns sectores, não terá sido a falta de regulação do Estado que causou a recente crise financeira que se espalhou a nível mundial. Tal como alguns autores mais críticos referem, só uma leitura "simplificada e superficial poderia considerar que o Estado se tinha retirado". Com efeito, sustentam ainda estes mesmos autores, "mais do que considerar a relação entre Estado e mercado na era neoliberal em termos de desregulação, pode ser mais útil examinar os modos pelos quais a financeirização se desenvolveu através dos órgãos reguladores velhos e novos" (Panitch \& Konings, 2009, p. 64-65). ${ }^{6}$

Aliás, no campo da educação aconteceu precisamente isto: o Estado nunca se retirou totalmente, apesar de, em determinados momentos, os discursos da redução do papel do Estado e do incremento da 
Protagonismos instáveis dos princípios de regulação e interfaces público/privado...

privatização serem ideologicamente ardilosos e, também por isso, fortemente persuasivos. Como procurarei sinalizar na secção seguinte deste texto, no que diz respeito a algumas orientações e políticas para a educação, o que parece ser mais expressivo, no contexto nacional, não é o esbatimento ou subalternização de um ou outro princípio de regulação, mas, antes, as porosidades e interacções entre os diferentes princípios de regulação.

\section{Quase-mercado e mercado em educação: interfaces público/privado}

Podendo ter alguma expressão no campo educacional, sobretudo ao nível da participação nos órgãos de direcção e gestão de escolas públicas e na concretização de parcerias várias entre estas e o terceiro sector, o apelo à sociedade civil (quer enquanto mercado, quer enquanto comunidade), tem vindo também a fazer-se em relativa sincronia com a introdução de mecanismos de privatização (sem mercado) e de lógicas de quase-mercado no campo (público) do Estado.

Uso aqui a expressão quase-mercado como referência genérica que inclui todas as formas possíveis em que esteja em desenvolvimento uma qualquer alteração, mais ou menos radical, nas lógicas públicas e estatais de provisão, financiamento e organização da educação escolar, sendo de admitir graus e procedimentos muito diferenciados que apenas excluem a privatização total dos serviços educativos. Neste sentido, a expressão quase-mercado (ou semi-mercado) referir-se-á à introdução de lógicas e valores de mercado no interior do sistema público estatal, dando conta inclusivamente de formas diversas de comparação, concorrência e concretização da liberdade de escolha entre o público e o privado, quando estas não levarem à privatização ou não forem induzidas por razôes de lucro, ainda que possam ser estimuladas por apoios financeiros ou subsídios específicos (como acontece com os vouchers ou cheques-ensino). Constituem ainda mecanismos de quase-mercado (porque induzidos ou propiciados pelo próprio Estado) os que se traduzem na concorrência entre organizações privadas, quando estas têm como objectivo ser escolhidas para funções de natureza lucrativa, através da realização de actividades específicas em estabelecimentos escolares públicos (por exemplo, a gestão privada de uma cantina ou a aquisição de um serviço privado para a segurança de uma escola pública). ${ }^{7}$ Assim, para os objectivos deste texto, utilizo a expressão quase-mercado 
para dar conta de uma série de mecanismos e dispositivos que favorecem o desenvolvimento de lógicas e valores de mercado, mas que não são rigorosamente mercado. Como referem alguns autores, "cada vez se utiliza mais a expressão quase-mercado para caracterizar a intenção de introduzir forças de mercado e formas de decisão próprias do sector privado na provisão da educação e dos serviços de bem-estar social" (Whitty, Power \& Halpin, 1999, p. 15). Ao contrário, a expressão mercado educacional parece-me mais adequada, se for utilizada para sinalizar a efectivação ou a indução da liberdade de escolha e da concorrência apenas entre escolas privadas, ou quando se tratar da oferta (no espaço do mercado) de outras iniciativas educativas privadas que visem o lucro. Neste sentido, a expressão quase-mercado é conotativa porque sugere a existência de valores, lógicas ou ideologias de mercado, mas não o mercado em sentido restrito. ${ }^{8}$

Tendo isso em consideração, podem ser equacionadas consequências (sociais e educacionais) diferentes, quando, por um lado, se trata de instituições educativas públicas (criadas, financiadas, reguladas e geridas exclusivamente pelo Estado) e que oferecem serviços gratuitos, tendencialmente gratuitos ou que não visam o lucro e se destinam a alunos de todas as classe sociais, ou quando, por outro lado, estão em causa instituições privadas em que os serviços educacionais são pagos com intuito de lucro, que podem seleccionar o público e que têm, muitas vezes, uma orientação mais classista e elitista e dependem, exclusiva ou predominantemente, da oferta e da procura no mercado.

Do meu ponto de vista, o facto de haver diferenças entre os dois modelos não significa que as consequências do mercado educacional sejam, a priori, piores ou mais benévolas do que as consequências do quase-mercado (ou vice-versa). Tudo depende dos valores e objectivos (políticos, sociais e educacionais) em causa num determinado modelo de organização escolar ou num determinado sistema educativo.

Considerando, por exemplo, a questão da democratização na escola pública, possivelmente as lógicas de quase-mercado poderão ter efeitos eventualmente mais nefastos do que as lógicas de mercado, dado que as primeiras se desenvolvem muitas vezes de forma oculta, podendo, sob o véu do discurso da igualdade de oportunidades, ser profundamente reprodutoras das desigualdades sociais e educacionais que atingem, sobretudo, os grupos sociais com menos capital social e cultural e com menos capacidade de descodificar criticamente (e fazer 
Protagonismos instáveis dos princípios de regulação e interfaces público/privado...

valer em seu proveito) as oportunidades e estratégias de sucesso e de mobilidade no interior do sistema. Em alguns países, como Portugal, a novidade relativamente recente dos dispositivos de quase-mercado (e a sua frequente fluidez e heterogeneidade) torna igualmente mais difícil perceber o seu funcionamento e adivinhar as suas consequências, sobretudo por parte de famílias em desestruturação e/ou envolvidas em processos mais ou menos irreversíveis de exclusão social, ou famílias já profundamente marcadas por (ou, numa determinada situação, mais conformadas com) processos de discriminação social e cultural. Isto não significa, todavia, que os grupos sociais desfavorecidos, ou com menos recursos para pagar escolas privadas, não procurem igualmente utilizar estratégias diferenciadas de escolha (neste caso, sobretudo, de escolha da escola pública), as quais visam, de modo idêntico, aumentar as oportunidades disponíveis para a escolarização e sucesso dos seus filhos. ${ }^{9}$

A indução de quase-mercados e/ou de mercados no campo educacional tem sido analisada partindo de múltiplos factores (cf., por exemplo, Zákia \& Oliveira, 2003; Barroso, 2003; Adriāo \& Peroni, 2005; van Zanten, 2005), ${ }^{10}$ entre os quais está a crítica ao monopólio da escola pública estatal, sobretudo quando este monopólio é considerado um obstáculo importante à liberdade constitucional de ensinar e de aprender, e um impedimento ao direito das famílias escolherem as escolas e os projectos educativos que julgarem mais convenientes para os seus filhos. Talvez por isso a valorização da liberdade de escolha educacional seja um dos aspectos mais consensuais no desenvolvimento dos fenómenos de mercado e de quase-mercado em educação. ${ }^{11}$ Aliás, a liberdade de escolha é um articulador muito consistente e útil ao compatibilizar (e dar sentido a) reivindicações de sectores ideológicos que defendem, em muitos casos, valores muito distintos, como é o caso dos neoconservadores e dos neoliberais: por um lado, da parte dos neoconservadores, a liberdade de escolha converge com o valor e centralidade da família na educação dos filhos e, portanto, com o direito de realizar escolhas que sejam compatíveis com os seus interesses; por outro lado, da parte dos neoliberais, a escolha é estruturante porque sem ela não é possível haver mercado competitivo, nem quase-mercado em educação.

Neste mesmo sentido, quando aumenta a pressão social para a escolha educacional, também são privilegiadas certas formas de avaliação (como os testes estandardizados e os exames nacionais) e a divulgação 
pública dos resultados escolares (como os rankings). Os próprios resultados da avaliação institucional, sobretudo quando decorrem de processos de avaliação externa, também podem ser publicamente divulgados e ter consequências semelhantes aos rankings. Porém, se é verdade que os resultados destas avaliaçóes continuam a estar na base de processos indutores de concorrência, comparação e emulação, nisso participando não apenas os alunos, mas, igualmente, e cada vez mais, os próprios professores e as organizaçóes educativas, também é verdade que os efeitos de quase-mercado em educação podem ser (e têm sido) conseguidos de formas muito mais diversificadas e subtis e, por vezes mesmo, mais eficazes do que através de rankings. ${ }^{12}$

Por outro lado, também o próprio mercado tem facetas e dimensões muito diversificadas. Como a este propósito chama a atenção Stephen Ball, "o mercado da educação já não é apenas uma questão de escolha e de concorrência entre instituições de ensino". Trata-se também de "um sistema de bens, serviços, experiências e percursos difuso, em expansão e sofisticado - alimentado pelo sector público e pelo sector privado" (2005, p. 11). ${ }^{13}$

No que diz respeito a Portugal, por exemplo, um dos fenómenos que tem vindo a ganhar crescente impacto educacional e económico, e que se alimenta precisamente dos défices do ensino público, é o das chamadas explicaçôes. As explicações constituem um verdadeiro mercado, na medida em que são aulas particulares pagas, dependem da iniciativa privada, visam fins lucrativos como consequência da prestação de um serviço, estão sujeitas à lei da oferta e da procura e são livremente escolhidas por alunos que necessitam de reforço ou complemento escolar, quer porque não conseguem atingir certos patamares em termos de desempenho académico, quer porque, sendo bons alunos, têm objectivos e expectativas de excelência que só podem (ou podem mais facilmente) ser realizados mediante este tipo oferta educativa. As explicaçōes, enquanto tutoria suplementar privada (private supplementary tutoring), ocorrem quer em empresas ou centros privados (até sob a forma de franchising), quer em espaços domésticos, mas sempre fora dos tempos normais de frequência da escola. ${ }^{14}$ Relativamente a Portugal, e não só, verificamos que as explicaçôes são um fenómeno que não é propriamente novo, estando o mesmo relacionado, entre outros factores, quer com a já longa crise da escola pública e suas consequências sociais e académicas, quer com o reforço das estratégias de preservação de 
Protagonismos instáveis dos princípios de regulação e interfaces público/privado...

(velhos) estatutos e privilégios de classe, quer, ainda, com estratégias para aumentar as probabilidades de concretizar expectativas de mobilidade social ascendente. Não sendo estes factores desconhecidos, eles ganham actualmente um novo sentido, quando a sua análise nos remete, directa ou indirectamente, para a configuração de um novo contexto nacional e global, cujos contornos mais expressivos (do ponto de vista cultural, económico e político-ideológico) se tornaram mais nítidos nas últimas décadas. É também neste novo contexto, que poderemos designar genericamente de neoliberal, ${ }^{15}$ que se geram e ampliam (não apenas a nível nacional, mas também a nível internacional) processos organizacionais, altamente lucrativos e tendencialmente de iniciativa privada, direccionados para o enquadramento de práticas de educação (e sobretudo de instrução), pretensamente mais eficazes em termos de impacto nos resultados académicos.

Inscrevendo-se igualmente numa agenda mais global - que é claramente direccionada para o objectivo da liberalização, da privatização e do desenvolvimento do mercado em educação -, não podem deixar de ser referidos os acordos feitos no âmbito da Organização Mundial do Comércio (OMC). Esta actua de forma diferente de outras organizações internacionais, na medida em que "funciona através da adopção de normas vinculatórias, em vez de recorrer a práticas persecutórias ou compensatórias", tendo igualmente a capacidade de "afectar os sistemas educativos e as práticas educativas num conjunto muito maior de actividades do que outras organizações" (Robertson, Bonal \& Dale, 2007, p. 206). No que diz respeito à problemática que tenho vindo a discutir, um dos principais compromissos internacionais que poderá afectar de forma crescente a educação consta do Acordo Geral sobre o Comércio de Serviços (GATS). Neste âmbito, entre muitos outros aspectos importantes, é previsível a alteração do papel do Estado nacional e dos padróes de funcionamento subordinados à concepção de bem comum, não apenas porque poderão diluir-se, de forma significativa, as funções tradicionais relativas ao financiamento, propriedade, provisão e regulação dos sistemas educativos públicos, mas também porque o derrube das barreiras tradicionais à importação e exportação de serviços educativos privados terá consequências na reconfiguração dos processos de acumulação e de legitimação. Se isto ganhar maior amplitude, como é previsível, "um hipotético sistema educativo mundial” não apenas levará a uma maior 
internacionalização das credenciais e diplomas, como impulsionará decisivamente a "globalização da produção e do consumo do conhecimento". Entre as diferentes razôes que podem levar a um aumento da oferta e da procura, num mercado educativo global altamente competitivo, está certamente o facto de este mercado poder "atrair capital educativo estrangeiro" capaz de contribuir para resolver problemas relativos à balança de pagamentos de alguns países, e ser também "uma estratégia para lutar contra o défice fiscal do Estado". ${ }^{16}$ Por sua vez, "a língua e a identidade nacional são funções vulneráveis num mercado global dominado pelas empresas educativas multinacionais", sendo que as bases da política nacional para a produção do conhecimento, bem como a sua apropriação e distribuição, serão também fortemente limitadas face à existência de um mercado livre, dentro de uma economia baseada no conhecimento (idem, ibid., p. 222-229). Nesse sentido, o sector mais permeável a este mercado global voltado para a comercialização dos serviços educativos é o ensino superior. Como refere a este propósito Santos (2005, p. 32), há já uma década que "a transnacionalização neoliberal da universidade ocorre sob a égide da Organização Mundial do Comércio”. Isto revela, aliás, que "a transformação da educação superior numa mercadoria educacional é um objectivo de longo prazo", o qual exige "a eliminação, progressiva e sistemática, das barreiras comerciais".

Sabendo dos modos específicos e vinculatórios de funcionamento da OMC e da vulnerabilidade de muitos países, no que diz respeito à construção e consolidação dos respectivos sistemas educativos nacionais - o que passa, frequentemente, pela própria incapacidade financeira para satisfazer uma demanda interna, nomeadamente no nível de ensino superior -, poderão perceber-se melhor as múltiplas consequências (sociais, económicas, culturais, identitárias...) e as novas e profundas assimetrias e desigualdades que estão sendo geradas pela ampliação da mercadorização da educação no espaço global. Nesta perspectiva, ainda que denunciando apenas uma das dimensões mais visíveis deste processo, ganha particular acuidade a afirmação de Jameson (2001) quando refere que o "imperialismo pós-moderno" no campo cultural está presente de forma evidente em organizações como a OMC. Certamente, isso é verdade, mas não é apenas no campo cultural que esta afirmação faz sentido, como demonstram muitas outras análises. 
Protagonismos instáveis dos princípios de regulação e interfaces público/privado...

\section{Para concluir, provisoriamente}

Procurei lembrar que os princípios de regulação (Estado, mercado e comunidade), que se desenvolveram no espaço do Estado-nação ao longo modernidade capitalista, têm vindo a confrontar-se com mudanças profundas nas últimas décadas. Estas mudanças, decorrentes nomeadamente da transnacionalização da economia e da emergência de novos actores e protagonistas subnacionais, nacionais e internacionais, têm questionado não apenas as funções e expectativas referenciadas a esses princípios de regulação, mas também a forma como esses mesmos princípios se actualizam face ao mundo contemporâneo, onde ganham importância e coexistem outras formas e instâncias de regulação. A este propósito, referi-me a protagonismos instáveis, permeáveis e abertos a interfaces, reconfigurando-se de forma mais líquida (na acepção de Bauman), sem os contornos rígidos ou duradouros dos períodos em que as relações entre os princípios de regulação eram construídas (ou, apenas, socialmente representadas) como sendo mais estanques ou coexistindo por justaposição. Voltando-me mais para o campo educacional, escolhi as interfaces entre o público e o privado, através dos mecanismos de mercado e quase-mercado, para ilustrar as porosidades que estão presentes nas relaçôes entre os próprios princípios de regulação, mostrando-me particularmente sensível ao facto de a privatização e mercantilização do sector público serem "cada vez mais complexas e totalizadoras". ${ }^{17}$ Aliás, esta tendência totalizadora tem uma evidente expressão no facto de a educação pública, como projecto essencial do Estado-nação, imbricada na afirmação e consolidação da cultura e identidade nacionais, estar hoje em dia ameaçada pela criação e realização de um mercado em educação e/ou pela existência de eficazes e variados dispositivos e mecanismos de quase-mercado, mas, sobretudo, pela emergência de um mercado mais agressivo e competitivo a nível global, como mostram bem os acordos da OMC relativos ao comércio de serviços educativos.

Perante este novo contexto, e face à pluralidade das novas formas e instâncias de regulação (de que não tratei nesta oportunidade), os velhos princípios de regulação da modernidade capitalista não desapareceram, mas são mobilizados e intersectados numa teia mais ampla e heterogénea de causalidades e de condicionantes nacionais e supranacionais. Por estas e outras razóes, repolitizar as agendas educacionais é 
cada vez mais urgente e indispensável para o fortalecimento de todas as capacidades de resistir e de pensar alternativas a esta mercadorização global da educação, que é, em algumas das suas dimensões, um novo e importante instrumento de acumulação capitalista com consequências perversas previsíveis.

\section{Recebido em fevereiro de 2010 e aprovado em março de 2010.}

\section{Notas}

1. É no século XIX "que o capitalismo se torna no modo de produção dominante nos países centrais e que a burguesia emerge como classe hegemónica. Daí para a frente, o paradigma da modernidade fica associado ao desenvolvimento do capitalismo" (Santos, 2000, p. 129).

2. Sigo aqui de perto a concepção de Boaventura de Sousa Santos que, em diferentes trabalhos, tem relacionado os princípios do Estado, do mercado e da comunidade com o pilar da regulação.

3. Como escreve Norberto Bobbio (1990, p. 33), "Na linguagem política de hoje, a expressão 'sociedade civil' é geralmente empregada como um dos termos da grande dicotomia sociedade civil/Estado (...). Negativamente, por 'sociedade civil' entende-se a esfera das relações sociais não reguladas pelo Estado".

4. Evidentemente, estas afirmaçōes são genéricas porque há especificidades que só podem ser atendidas e consideradas numa análise mais aprofundada e num período histórico mais longo.

5. Mas, se há uma concepção neoliberal de sociedade civil que se confunde com o terceiro sector e que pode, também por isso, ser posta em questão (cf. Montaño, 2002), há também outras concepções que sugerem alternativas de revalorização desse mesmo terceiro sector, no sentido de ser possível, em determinadas condições, a "reinvenção solidária e participativa do Estado" (Santos, 2006, p. 317-349).

6. E concluem: "En vez de defender la clase de iniciativas de vuela a la regulación de arriba abajo que simplesmente reinstalan la hegemonía financiera, lo que se necesita es sondear intelectual, cultural, así como políticamente - si esta crisis podría proporcionar una oportunidad de renovación del tipo de perspectiva radical que anticipa una alternativa sistémica al capitalismo global” (Panitch \& Konings, 2009, p. 78).

7. De acordo com Clive Belfield e Henry Levin, a "privatização educativa" (em sentido amplo) pode ser feita utilizando uma ou mais das seguintes estratégias: aumento da participação de operadores privados, aumento do financiamento directo por parte dos usuários, e aumento do controlo e da escolha das escolas pelos pais. Através destas medidas, em vez da privatização total, ocorre antes a criação de um "semimercado", em que a competição entre o público e o privado não é motivada pelo lucro, sendo instrumentos deste semimercado os cheques-ensino (vouchers) ou outras formas de financiamento, a desregulamentação da escola pública, a contratação de serviços específicos, não directamente educativos, de organizaçóes privadas (serviço de cantinas, limpeza, segurança, transportes ou mesmo a gestão), bem como os benefícios fiscais e subsídios às famílias e a atribuição

Educ. Soc., Campinas, v. 31, n. 113, p. 1137-1156, out.-dez. 2010

Disponível em <http://www.cedes.unicamp.br> 
de bolsas para a frequência de escolas privadas, entre muitas outras estratégias possíveis (cf. Belfield \& Levin, 2004).

8. A afirmação é inspirada em Dale (1995, p. 140-141), quando refere que "o termo mercado é muito mais conotativo do que denotativo", uma vez que, no contexto político analisado por este autor, ele "opera como uma metáfora ou slogan mais do que um guia explícito e detalhado de ação". Por analogia, parece-me que a observação é também válida, em determinadas situaçôes, no que diz respeito ao quase-mercado.

9. Tendo como referência um trabalho de pesquisa, desenvolvido no Rio de Janeiro, cujo objecto é a "disputa por escolas públicas que não poderiam ser caracterizadas como 'de elite' ou 'de excelência", Marco Costa e Mariane Koslinski escrevem: "Entre os amplos segmentos da população desprovida de meios de acesso a essas escolas de elites, podemos encontrar renhidas lutas pela oportunidade de aceder a uma oferta escolar considerada de qualidade superior às demais dentre o espectro das que é plausível aspirar”. E continuam: "Nossa pesquisa se dedica a investigar os processos de escolha e de acesso escolar em um contexto que denominamos 'quase-mercado oculto'. Isto é, pretende observar o caso brasileiro - em contraste com locais onde há políticas deliberadas de escolha escolar - e, frente à ausência de regulação, os mecanismos de segmentação que se manifestem em meio à complexa hierarquia escolar existente nas redes 'comuns'. Suspeitamos que, em nosso caso, o silêncio e a quase ausência de regras para a disputa por vagas nas escolas que atendem à imensa maioria da população promovem a desigualdade de oportunidades escolares de forma mais severa que a criticada pelos opositores de políticas de school choice. Enfim, o processo parece acentuar características promotoras de desigualdade social, ampliando as chances de quem já desfruta de algum benefício, frequentemente associado ao patrimônio de relaçôes sociais" (Costa \& Koslinski, 2009, p. 2).

10. Uma das primeiras propostas de análise das mudanças nas políticas públicas, a partir do conceito de quase-mercado, encontra-se no muito referenciado trabalho de Julian Le Grand (1991).

11. Parecendo justamente incluir tanto a possibilidade do mercado, como a possibilidade do quase-mercado, Barroso e Viseu (2003, p. 899) advertem: “(...) as forças e os interesses em presença no processo de definição, coordenação e execução das políticas e acção educativas são muito mais amplos e diversificados do que a dicotomia Estado-mercado abrange (...). Na verdade, se a 'livre-escolha' da escola é um dos instrumentos mais poderosos para a criação de um mercado educativo (...) o certo é que há lógicas de interacção e escolha que não se inserem, necessariamente, num modelo concorrencial de mercado".

12. Como escreve Martins (2009), a gestão e promoção da imagem da escola pode ser uma forma de substituir (ou de neutralizar) a consequência dos rankings, mantendo igualmente, por este processo, a indução de efeitos de quase-mercado nas escolas públicas, mesmo naquelas onde os próprios resultados dos alunos não são tão favoráveis como seria desejável. Por outro lado, no estudo de Antunes e Sá (2010, p. 141), "A publicitação de diversas 'ligas' nacionais de escolas [rankings] constitui uma pressão adicional, face à qual as escolas, segundo os seus responsáveis, mobilizam parte dos seus recursos materiais e simbólicos para alimentar uma imagem favorável e o marketing capaz de a potenciar".

13. Este autor refere ainda a utilização crescente de uma "combinação de instituiçōes estatais e/ ou privadas" através das quais os pais - "ser pai ou mãe é uma tarefa cada vez mais difícil, exigente e profissionalizada" - viabilizam o acesso dos filhos a complementos educativos pagos, serviços de consulta e acompanhamento psicológico, actividades de desenvolvimento físico, frequência e acompanhamento de diferentes actividades de lazer e tempos livres, entre muitas outras. $\mathrm{O}$ aumento da procura destas actividades não-formais, para além dos 
tempos normais de escolarização, dentro ou fora da escola, tem vindo a acontecer também em Portugal, de forma mais notória nos últimos anos. A este propósito, ver, por exemplo, Palhares (2009).

14. Para um excelente trabalho sociológico sobre este tema - que reúne, em capítulos de autoria diversa, algumas das dimensões mais expressivas sobre o fenómeno das explicações em Portugal e noutros países -, ver Costa, Neto-Mendes e Ventura (2008).

15. Para uma abordagem de alguns dos traços mais marcantes do neoliberalismo na educação, ver, por exemplo, Silva (2007).

16. Como refere Siqueira (2004, p. 145-146), "Os países mais ricos, com a maioria da população escolarizada, uma taxa de natalidade decrescente e amplos sistemas educacionais em funcionamento, estão se apresentando como um mercado restrito para a atuação de empresas no setor educacional. Por outro lado, os países em desenvolvimento - onde hoje se encontra a maior parte da população em idade escolar e, portanto, onde há uma grande demanda potencial para a oferta de ensino nos vários níveis - são os alvos privilegiados dessa busca dos grupos empresariais por novos mercados".

17. Como diz Ball (2004, p. 1121), "a privatização e mercantilização do setor público são cada vez mais complexas e totalizadoras e ambas fazem parte de um acordo de política global”. Para um leitura mais densa sobre estas questôes, ver ainda Ball (2007).

\section{Referências}

ADRIÃO, T.; PERONI, V. (Org.). O público e o privado na educação: interfaces entre Estado e sociedade. São Paulo: Xamã, 2005.

AFONSO, A.J. Estado, mercado, comunidade e avaliaçãa: esboço para uma rearticulação crítica. Educação \& Sociedade, Campinas, v. 20, n. 69, p. 139-164, 1999.

AFONSO, A.J. Avaliação educacional: regulação e emancipação. 4. ed. São Paulo: Cortez, 2009.

ANTUNES, F.; SÁ, V. Notas, pautas e vozes na escola: exames, rankings e regulação da educação. In: Esteban, M.T.; Afonso, A.J. (Org.). Olhares e interfaces: reflexões críticas sobre a avaliação. São Paulo: Cortez, 2010. p. 112-146.

BALL, S. Performatividade, privatização e o pós-Estado do bem-estar. Educação \& Sociedade, Campinas, v. 25, n. 89, p. 1105-1126, 2004.

BALL, S. Educação à venda. Viseu: Pretexto, 2005.

BALL, S. Education plc: understanding private sector participation in public sector education. London: Routledge, 2007. 
Protagonismos instáveis dos princípios de regulação e interfaces público/privado...

BARROSO, J. (Org.). A escola pública: regulação, desregulação e privatização. Porto: Asa, 2003.

BARROSO, J.; VISEU, S. A emergência de um mercado educativo no planeamento da rede escolar: de uma regulação pela oferta a uma regulação pela procura. Educação \& Sociedade, Campinas, v. 24, n. 84, p. 897-921, 2003.

BELFIELD, C.; LEVIN. H.M. A privatização da educação: causas e implicações. Porto: Asa, 2004.

BOBBIO, N. Estado, governo, sociedade: para uma teoria geral da política. Rio de Janeiro: Paz \& Terra, 1990.

COSTA, J.A.; NETO-MENDES, A.; VENTURA, A. Xplica: investigação sobre o mercado das explicações. Aveiro: Universidade de Aveiro, 2008.

COSTA, M.; KOSLINSKI, M. Escolha, estratégia e competição por escolas públicas: pensando a ecologia do quase-mercado escolar. Comunicação ao $33^{\circ}$ Encontro Nacional da ANPOCs, 2009.

DALE, R. O marketing do mercado educacional e a polarização da educação. In: Gentili, P. (Org.). Pedagogia da exclusão: crítica ao neoliberalismo em educação. Petrópolis: Vozes, 1995. p. 137-168.

ESTÊVÃO, C.V. Redescobrir a escola privada portuguesa como organização. Braga: Universidade do Minho, 1998.

GAMBLE, A. The free economy and the strong State. 2. ed. London: Macmillan, 1994.

JAMESON, F. Globalização e estratégia política. In: SADER, A. (Org.). Contracorrente: o melhor da New Left Review em 2000. São Paulo: Record, 2001. p. 133-158.

LE GRAND, J. Quasi-markets and social policy. The Economic Journal, London, v. 101, p. 1256-1267, 1991.

LIMA, L.C.; AFONSO, A.J. Políticas públicas, novos contextos e actores em educação de adultos. In: LimA, L.C. (Org.). Educação não escolar de adultos: iniciativas de educação e formação em contexto associativo. Braga: Universidade do Minho, 2006. p. 205-229. 
MARTINS, M.F. Gerencialismo e quase-mercado educacional: a acção organizacional numa escola secundária em época de transição. 2009. Tese (Doutorado) - Instituto de Educação e Psicologia, Universidade do Minho, Braga.

MONTAÑO, C. Terceiro setor e questão social: crítica ao padrão emergente de intervenção social. São Paulo: Cortez, 2002.

NOGUEIRA, M.A. As possibilidades da política: ideias para a reforma democrática do Estado. São Paulo: Paz \& Terra, 1998.

NOZICK, R. Anarquía, Estado y utopía. México: Fondo de Cultura Económica, 1988.

PALHARES, J.A. Reflexões sobre o não-escolar na escola e para além dela. Revista Portuguesa de Educação, Braga, v. 22, n. 2, p. 53-84, 2009.

PANITCH, L.; KONINGS, M. Mitos de la desregulación neoliberal. New Left Review, Madrid, n. 57, p. 63-78, 2009.

ROBERTSON, S.; BONAL, X.; DALE, R. El agCs y la industria de los servicios educativos. In: Bonal, X. et al. (Org.). Globalización y educación: textos fundamentales. Buenos Aires: Miño y Dávila, 2007. p. 205-232.

SANTOS, B.S. A crítica da razão indolente: contra o desperdício da experiência. Porto: Afrontamento, 2000.

SANTOS, B.S. A universidade no século XXI: para uma reforma democrática e emancipatória da universidade. São Paulo: Cortez, 2005.

SANTOS, B.S. A gramática do tempo: para uma nova cultura política. Porto: Afrontamento, 2006.

SILVA, M.A. A educação num contexto de hegemonia ideológica neoliberal. Currículo sem Fronteiras, Porto Alegre, v. 7, n. 1, p. 206-242, 2007.

SIQUEIRA, A. A regulamentação do enfoque comercial no setor educacional via OMc/Gats. Revista Brasileira de Educação, Rio de Janeiro, n. 26, p. $145-156,2004$. 
Protagonismos instáveis dos princípios de regulação e interfaces público/privado...

VAN ZANTEN, A. Efeitos da concorrência sobre a atividade dos estabelecimentos escolares. Cadernos de Pesquisa, São Paulo, v. 35, n. 126, p. 565-593, 2005.

WHITTY, G.; POWER, S.; HALPIN, D. La escuela, el Estado y el mercado: delegación de poderes y elección en educación. Madrid: Morata, 1999.

ZÁKIA, S.; OLIVEIRA, R. Políticas de avaliação da educação e quase-mercado no Brasil. Educação \& Sociedade, Campinas, v. 24, n. 84, p. 873-895, 2003. 